\title{
Krachtvoert: effect evaluation of a Dutch healthful diet promotion curriculum for lower vocational schools
}

\author{
Marloes K Martens' ${ }^{1}$, Patricia Van Assema ${ }^{1, *}$, Theo GWM Paulussen², \\ Gerard Van Breukelen ${ }^{3}$ and Johannes Brug ${ }^{4}$ \\ ${ }^{1}$ Nutrition and Toxicology Research Institute Maastricht (NUTRIM), Department of Health Education and Health \\ Promotion, Maastricht University, PO Box 616, 6200 MD Maastricht, The Netherlands: ${ }^{2}$ Business Unit Prevention \\ \& Care, TNO Quality of Life, Leiden, The Netherlands: ${ }^{3}$ Department of Methodology and Statistics, Maastricht \\ University, Maastricht, The Netherlands: ${ }^{4}$ EMGO Institute, VU University Medical Centre, Amsterdam, \\ The Netherlands
}

Submitted 24 August 2006: Accepted 29 March 2007: First published online 3 July 2007

\begin{abstract}
Objective: The aim of this study was to assess the behavioural effects of a schoolbased healthful diet promotion intervention implemented in lower vocational schools.

Design: A cluster-randomised pre-test-post-test experimental design was used, and data were collected by means of written questionnaires.

Setting: Students of 18 Dutch lower vocational schools.

Subjects: The final sample consisted of 10 experimental schools with 13 teachers, 37 classes and 879 students, and eight control schools with 10 teachers, 31 classes and 734 students (total $n=1613$ ).

Results: Fixed regression analyses revealed beneficial effects on the behavioural measures relating to fruit intake (as assessed by a food frequency measure and fruit consumption during the previous day), and most behavioural measures related to high-fat snack intake (food frequency measure, and number of snacks and total fat intake from snacks during the previous day). The behavioural effects relating to breakfast habits were limited. Some positive behavioural effects occurred in the total target population, others mainly or only among students with more unfavourable intakes at baseline. Mixed regression analysis found comparable regression coefficients for the behavioural outcomes, but the effects related to fruit intake were no longer statistically significant.

Conclusions: Although we did not find the expected effects on all outcome indicators, the total pattern of results suggest that Krachtvoer offered a surplus value over existing curricula. However, some programme elements need to be revised to improve effectiveness and prevent negative effects, and more information is needed about the long-term effects of the programme.
\end{abstract}

Keywords
Adolescents
Nutrition
Effect evaluation

In The Netherlands, as in most European countries, few evidence-based interventions are available to encourage healthful dietary habits. At the time of writing, no comprehensive studies into the behavioural effects of healthful diet interventions for Dutch children and adolescents had been completed. The availability of such healthful diet interventions is important, since unhealthy eating habits, such as low intake of fruit and high intake of saturated fat, are very common in youngsters and may contribute to the high incidence of cardiovascular dis-

\footnotetext{
† We will use the Dutch title of the programme throughout this article. A possible translation is Power Food, but this does not reflect the play on words made possible by the Dutch language.
}

eases, diabetes and certain types of cancer at a later age $^{1-3}$. The diet-related prevalence of adolescent overweight and obesity is an additional rapidly growing problem $^{4,5}$. It is particularly important to develop effective interventions for young people, as healthful eating at an early age may be an important determinant of dietary choices in later life $\mathrm{e}^{6,7}$.

There are examples of evidence-based programmes for youngsters available especially in the United States ${ }^{8-11}$. More recently, results from a few school-based interventions in Europe have been published, e.g. Bere et al. ${ }^{14}$. An examination of studies evaluating these programmes revealed a number of elements that are helpful in developing a successful nutrition education programme ${ }^{9-18}$. 
For instance, a behaviourally focused approach that targets specific behaviours was found to increase the likelihood of behavioural changes more than interventions focused on nutrition in general ${ }^{9-12}$. Nutrition education interventions should also provide opportunities for adolescents to taste and enjoy a wide variety of healthful foods in positive social-affective contexts, and increase the availability of healthful foods ${ }^{10,15}$. Furthermore, interventions should include self-evaluation or selfassessment with a personal feedback component ${ }^{10,11,13}$. Other features that have been found to contribute to effectiveness are adequate time for the intervention and adequate intensity, as programmes with longer duration and more contact hours achieve better results than shorter programmes $^{9-11,15}$

This article describes the results of a trial to assess the effects on dietary behaviours of the Dutch healthful diet promotion programme called Krachtvoer for 12-14-yearold students of lower vocational schools (preparatory secondary vocational education). The programme focused on this age group because it is especially when children transfer from primary school to secondary school that their eating habits are likely to change and become less healthful ${ }^{7,12}$. Intervening at this age may therefore help to prevent unhealthy eating behaviour becoming habitual. The programme targeted students of lower vocational schools, since they tend to belong to groups with lower socio-economic position, which are known to have less-favourable diets than groups with higher socioeconomic position ${ }^{13,14}$. The programme focused on the intake of fruit, high-fat snacks and breakfast, because these behaviours are under the students' volitional control and can be influenced during school hours or are important for school performance. The programme built upon earlier international attempts to improve adolescents' diets $^{8-12}$, which were adapted to the Dutch situation.

\section{Method}

\section{Intervention}

In the development of the programme, some key aspects of intervention mapping were used ${ }^{19}$. Intervention mapping is a framework for effective decision-making at each step in the process of developing, implementing and evaluating theory-based and evidence-based health education programmes. As recommended by intervention mapping, we systematically used the available theories and evidence to make decisions on programme goals and target group, the behaviour change methods and strategies, the programme design, and implementation strategies. We conducted a thorough needs assessment to gain further insight into specific personal and situational determinants of the target behaviours and opinions on nutrition and nutrition education in our specific target population, i.e. Dutch adolescents in lower vocational schools ${ }^{20,21}$. The overall aim of the programme was to increase the consumption of fruit and fruit juice, to decrease the consumption of high-fat snacks and to increase breakfast frequency and quality. We defined programme objectives by breaking down the dietary behaviours under study into specified performance objectives (Table 1). The programme consisted of eight school lessons lasting $50 \mathrm{~min}$ each. A combination of materials was used: various so-called 'task forms' for the lessons, postcards and posters, a 'survival kit' (a lunchbox with three healthful food items, viz. a piece of fruit, a health food snack and a breakfast product, and a flyer), a magazine, a video, a website, a take-home bag with a newsletter and food items for the parents, taste-testing of various products and a manual to instruct the teacher in providing the different lessons.

\section{Study design and sample}

The study used a cluster-randomised pre-test-post-test experimental design. Twenty-five lower vocational schools were recruited in the southern and central parts of The Netherlands. To avoid too large a variation between the schools in the study, inclusion criteria were (1) a maximum of $50 \%$ students of foreign origin and (2) implementation of one of the three most commonly used nutrition education curricula in The Netherlands. Each participating school was asked to select a number of classes in such a way so as to have 50 to 150 students in the targeted age group participating in the study in each school. After recruitment, the schools were randomly assigned to the experimental condition (13 schools) or the control condition (12 schools). Control schools kept using their usual nutrition education curriculum and experimental schools replaced their usual curriculum with the Krachtvoer programme.

\section{Measures}

Students were requested to complete a baseline questionnaire in the classroom (September 2002) and a posttest questionnaire 3 months later (December 2002). The teachers supervised the completion of the questionnaires. The questionnaire was a classroom activity, but students were told that they could perform another task in case they objected to the completion of the questionnaire. Baseline and post-test questionnaires were matched on the basis of school, class and date of birth.

\section{Dietary intakes}

Dietary intakes were assessed by using food frequency questions and by using a self-administered 24-hour recall. Consumption of fruit was assessed using the fruit questions from a validated fruit and vegetable food-frequency questionnaire $^{22}$. In two separate items, students indicated 
Table 1 Overview of the 'Krachtvoer' programme: phases, lessons, performance objectives and materials

\begin{tabular}{llc}
\hline Phase & Lesson & Performance objective \\
\hline 1 & 1 & Make students enthusiastic about the
\end{tabular}
programme

$\begin{array}{ll}2, & \text { Assess intake } \\ 3 & \text { Compare intake with recommendations }\end{array}$

4 (start) Indicate reasons for discrepancies between own intake and recommended levels

2 4 (end),
5,
6,
7 (start)

3 7 (end)

Implement solutions
Three different postcards introducing the programme name, the three cartoon characters and the internet site

Posters matching the design of the postcards

Action form for a quiz with questions related to the three behaviours

Survival kit with three healthful food items and flyer with an overview of the programme

Information form and action form with a fruit juice test to distinguish real fruit juices from fruit drinks containing sugar

Three question forms to assess fruit and snack consumption, and breakfast habits

Three information forms with fruit, breakfast and snack consumption guidelines

Three question forms to compare own fruit, breakfast and snack intake with guidelines

Question form to help students understand their own reasons for not performing the healthful behaviours

Information forms and action forms to invent a healthful fruit, snack or breakfast recipe for a recipe contest

Action form to do taste-testing and experience that unfamiliar healthful foods can be tasty

Action form to make a fruit shake and experience that fruit can be tasty

Taste-testing fruits and experience that fruit can be tasty

Kiwi-eating contest, letting students experience that fruit can be eaten without getting sticky hands

Action form to watch a video with several commercials and learn how to deal with social influences on eating behaviour

Take-home bag with food items, and a newsletter including recipes and tips for parents to support their children

Action form to test nutrition knowledge

Magazine providing facts, tests, puzzles, a horoscope, role model stories, recipes and support for the programme

Internet site presenting information about fruit, breakfast and snacking, several tests, recipes and support for the programme

Computer snack test aimed at providing relevant knowledge

Question form to formulate specific and achievable goals to change behaviour

Magazine including useful suggestions for achieving dietary changes

Question form to evaluate students' new behaviour on how many days a week they consumed fruit and fruit juice and the number of servings of fruit and fruit juice they consumed on these days. Frequency and quantity were multiplied to obtain estimates of mean consumption of fruit in servings per day, and of fruit juice in glasses per day. Two items measuring snack consumption were derived from a validated fat-intake questionnaire ${ }^{23}$. Students were asked to indicate the number of days a week they usually consumed sweets and savoury snacks, as well as the amount of sweets and savoury snacks they consumed on these days. Frequency and quantity were multiplied to obtain estimates of the mean consumption of sweets and savoury snacks in servings per day.

In one item, students were asked on how many days per week they normally ate breakfast. Students also wrote down yesterday's fruit and fruit juice consumption and snack consumption, and today's breakfast consumption.
Nutrient intakes were calculated using the Becel nutrition programme (2002) and Dutch food codes and weights ${ }^{24}$, i.e. total fat and saturated fat for yesterday's snack consumption, and total fat, saturated fat, carbohydrates, protein, vitamin C and sugar for today's breakfast consumption.

\section{Analysis}

Analyses were performed using SPSS (version 11; SPSS, 2001), unless mentioned otherwise.

Descriptive statistics (percentages and means) were used to describe key participant characteristics and variable scores for the experimental and control groups, both at baseline and post-test. Multiple logistic regression of dropout (yes/no) on baseline variables and treatment condition was done to identify causes of dropout and 
thereby also as potential bias in analyses of post-test data. This dropout analysis was done twice: once with all schools of which baseline questionnaires were received, and once with all schools of which baseline and post-test questionnaires were received. An $\alpha=0.05$ two-tailed test was used.

In all effect analyses, persons with a missing post-test value due to school, class or individual dropout were included by replacing the missing post-test value with the baseline value (i.e. the last observation carried forward method). From this point, these analyses will be referred to as intention-to-treat analyses. Since the fruit and snack frequencies variables were not normally distributed, the data were transformed by taking the square root of the frequency scores, which improved the variance and the normality. The breakfast frequency variable was extremely skewed and was therefore dichotomised based on the Dutch breakfast recommendation (i.e. at least 5 days a week vs. fewer days).

Post-test differences between study conditions were first analysed with a fixed linear or logistic regression. Each post-test measure of behaviour was regressed on the study group, gender, age, baseline value of the outcome at hand and interaction terms of the study group with gender, age and baseline value. To simplify the interpretation of study group effects in the possible presence of interactions, the baseline value was always centred (i.e. the overall sample mean was subtracted from each individual baseline value such that the baseline mean became zero), and gender and age were centred if they interacted with treatment. Due to this centring, the $B$-value and significance of the treatment effect can be interpreted as average treatment effect in the presence of interaction with covariate. Non-significant interactions were removed from the model one by one. In case of a significant interaction with the baseline value, the sample was stratified into three approximately equally large subgroups based on the baseline value. Also, multilevel (mixed) regression analyses were conducted to verify the behavioural outcomes that were significant in the fixed regression analyses, by taking intra-class correlation into account ${ }^{25}$. Mixed logistic regression analyses were run in Mlwin $1.10 .0007^{26}$. More specifically, the fixed regression model was extended with a random school effect and a random class effect. Since schools were randomised, no mixed interaction of treatment by school or class could be tested. In all analyses, an $\alpha=0.05$ two-tailed test was used. An $\alpha=0.05$ one-tailed test was used for testing intra-class correlations of the primary outcomes ${ }^{25,27}$.

\section{Results}

\section{Response rates, attrition and respondents}

Before the actual start of the baseline measurements, one experimental school and two control schools withdrew because of time problems and because one of the teachers left the school. The baseline questionnaires of another experimental school and two control schools were never received, even though two schools claimed to have sent the completed questionnaires to the study centre. One experimental school was excluded during the study, as its staff did not implement the programme and had the questionnaires completed by students who were not supposed to be in the study. The final sample for the intention-to-treat analyses thus consisted of 10 experimental schools with 13 teachers, 37 classes and 879 students, and eight control schools with 10 teachers, 31 classes and 734 students (total $n=1613$ ). Post-test questionnaires were received from 10 experimental schools with 13 teachers, 37 classes and 781 students, and six control schools with eight teachers, 21 classes and 469 students. The main reasons for not receiving post-test questionnaires from schools and classes were postal delivery problems. Of all participating schools and classes, 98 individual experimental students and 107 control students did not complete the post-test. The main reason was absence during the hours when they were supposed to complete the questionnaire. None of the students objected to completing the questionnaire. Multiple logistic regression of dropout on baseline variables showed that girls, older students and control group students dropped out significantly more often than boys, younger students and intervention group students, respectively. The treatment group and age effect on dropout remained significant and the gender effect disappeared when the dropout analyses were limited to the schools of which baseline and post-test questionnaires were received.

Boys and girls were equally represented in the sample. In the final sample, $32 \%$ of the students were aged 12 years or younger, $53 \%$ were 13 years old and $15 \%$ were 14 years or older. The majority of the students had parents who had both been born in The Netherlands (83\%). Mean variables scores at baseline and post-test with individuals as unit of analysis are presented in Table 2. Very similar mean values were found using schools instead of individuals as unit of analysis.

\section{Dietary intakes at post-test}

The results of the effect analyses of the dietary intakes are summarised in Table 2. Note that the centring of baseline values allows the main effect of the study group (i.e. regression coefficient or $B$-value) to be interpreted as an average treatment effect even in the presence of treatment-by-baseline interaction. No convincing interaction effects of condition with age or gender were found.

\section{Fruit intake at post-test}

At post-test, respondents in the experimental condition reported a higher fruit frequency and higher fruit consumption during the previous day (main treatment effects) than the control group. The main treatment effect 
Table 2 Mean and SD, with students as units of analysis, of fruit consumption, snacking and breakfast behaviour at baseline (T0) and post-test (T1) by study group, and post-test group differences adjusted for baseline, age and gender indicating significant differences between the intervention group and the control group based on fixed regression analyses

\begin{tabular}{|c|c|c|c|c|c|c|c|c|}
\hline & \multicolumn{2}{|c|}{ Intervention group $(n=879)$} & \multicolumn{2}{|c|}{ Control group $(n=734)$} & \multirow{2}{*}{$\begin{array}{l}\text { Adjusted }^{*}(B \text {-value for } \\
\text { difference between groups at T1) }\end{array}$} & \multicolumn{3}{|c|}{$\begin{array}{l}\text { Subgroup analyses of centred } \\
\text { baseline scoret ( } B \text {-value) }\end{array}$} \\
\hline & T0 & T1 & T0 & T1 & & Low & Medium & High \\
\hline \multicolumn{9}{|l|}{ Fruit (juice) intake (in mean; SD) } \\
\hline Fruit frequency (servings per day) & $0.91(0.81)$ & $1.10(0.86)$ & $0.89(0.75)$ & $0.96(0.81)$ & $0.04^{3}$ & 0.06 & $0.06^{3}$ & 0.01 \\
\hline Yesterday's fruit consumption (servings) & $0.95(0.96)$ & $1.20(1.00)$ & $0.96(0.93)$ & $1.10(1.01)$ & $0.13^{2}$ & $0.33^{1}$ & $0.13^{3}$ & -0.11 \\
\hline Fruit juice frequency (glasses per day) & $1.03(0.71)$ & $0.99(0.69)$ & $0.95(0.69)$ & $0.98(0.70)$ & -0.04 & 0.07 & -0.01 & $-0.16^{3}$ \\
\hline Yesterday's fruit juice consumption (glasses) & $1.04(0.77)$ & $1.11(0.66)$ & $0.91(0.77)$ & $1.07(0.71)$ & -0.03 & 0.08 & -0.02 & $-0.12^{1}$ \\
\hline \multicolumn{9}{|l|}{ Snack intake (in mean; SD) } \\
\hline Snacking frequency (pieces per day) & $1.80(1.38)$ & $1.70(1.32)$ & $1.88(1.46)$ & $1.84(1.44)$ & -0.02 & 0.03 & 0.03 & $-0.08^{2}$ \\
\hline \multicolumn{9}{|l|}{ Yesterday's snack consumption } \\
\hline Pieces & $1.96(1.52)$ & $1.82(1.43)$ & $2.05(1.56)$ & $1.95(1.54)$ & -0.08 & $0.20^{3}$ & 0.04 & $-0.57^{1}$ \\
\hline Total fat $(\mathrm{g})$ & $16.63(20.45)$ & $15.9(19.82)$ & $16.65(19.49)$ & $18.16(26.16)$ & -1.90 & 0.93 & 1.23 & $-5.64^{3}$ \\
\hline Total saturated fat $(\mathrm{g})$ & $6.49(7.83)$ & $6.29(7.77)$ & $6.32(6.96)$ & $6.61(7.68)$ & -0.25 & 0.43 & 0.87 & -1.00 \\
\hline \multicolumn{9}{|l|}{ Breakfast intake (in mean; SD) } \\
\hline \multicolumn{9}{|l|}{ Breakfast frequency } \\
\hline In acc. with guidelines & $79 \%$ & $78 \%$ & $79 \%$ & $77 \%$ & $0.01 \ddagger$ & & & \\
\hline Not in acc. with guidelines & $21 \%$ & $22 \%$ & $21 \%$ & $23 \%$ & & & & \\
\hline \multicolumn{9}{|l|}{ Yesterday's breakfast consumption } \\
\hline Total fat (g) & $8.30(15.27)$ & $7.55(7.58)$ & $8.42(8.65)$ & $7.93(8.49)$ & -0.37 & 0.34 & 0.28 & -1.30 \\
\hline Total saturated fat $(\mathrm{g})$ & $3.31(2.86)$ & $3.18(2.93)$ & $3.63(4.59)$ & $3.45(4.80)$ & -0.07 & 0.17 & 0.26 & $-1.06^{3}$ \\
\hline Total carbohydrates (g) & 38.49 (26.73) & $37.30(26.70)$ & $39.73(30.00)$ & $38.96(30.63)$ & -1.13 & 1.83 & -1.06 & -5.41 \\
\hline Total protein $(\mathrm{g})$ & $9.88(7.32)$ & $9.30(7.34)$ & $9.96(7.98)$ & $9.44(8.11)$ & -0.13 & 0.64 & 1.50 & -1.41 \\
\hline Total vitamin C $(\mu \mathrm{g})$ & $12.73(24.94)$ & $15.59(27.07)$ & $14.13(28.77)$ & $14.22(29.95)$ & 2.09 & 1.03 & $5.42^{2}$ & -3.70 \\
\hline Total sugar (g) & $17.10(14.02)$ & $17.10(14.45)$ & $17.33(14.76)$ & $17.34(15.51)$ & -0.20 & 1.36 & 0.46 & -2.55 \\
\hline
\end{tabular}

\section{$\mathrm{SD}$ - standard deviation}

Adjusted for age, gender and baseline, corresponding with the unstandardised regression weight of the binary predictor study group $(0=$ control condition and $1=$ intervention condition). One interaction with age (yesterday's total fat consumption $B$-value $=-1.01, P=0.04$ ) was found and one interaction effect with gender (fruit frequency $B$-value $=-0.12, P=0.00$ ) was found.

+Only reported when a significant interaction between study group and centred baseline value was found. The mean $B$-value of the subgroups can differ from the total $B$-value because it was not always possible to stratify the sample in three equal tertiles.

$\ddagger B$ as based on logistic regression.

$P=0.000$ two-tailed.

$3 P \leq 0.05$ two-tailed. 
on fruit frequency was due to an effect in the subgroups of students with a medium baseline frequency value. The main treatment effect on fruit consumption during the previous day was due to an effect in the subgroup of students with the least desirable baseline values.

With respect to the outcomes of fruit juice frequency and fruit juice consumption during the previous day, we found no main effect, but an interaction effect in the sense that the intervention had a significant but adverse effect among the students with the most desirable baseline values.

The mixed regression analyses yielded a class effect regarding fruit consumption during the previous day $(P<0.05$ one-tailed, intra-class correlation 0.14$)$, and fruit juice consumption during the previous day $(P<0.05$ one-tailed, intra-class correlation 0.17). No convincing differences in $B$-values were found compared to the fixed analyses, but the effects on fruit frequency and fruit consumption during the previous day were no longer significant in the mixed analyses ( $P$ for fruit frequency $=0.23$ and $P$ for fruit consumption during the previous day $=0.06$ ).

\section{Snack intake at post-test}

With respect to snack frequency and total fat intake from snacks consumed during the previous day, we found an interaction effect in the sense that the intervention had a beneficial effect among students with the least desirable baseline intakes. As regards the number of snacks consumed during the previous day, the intervention had an adverse effect among students with the most desirable baseline value, but a beneficial effect among students with the least desirable baseline value.

Mixed regression analysis for snack behaviour did not show any school or class effects and no convincing differences in $B$ - or $P$-values were found compared to the fixed regression analysis.

\section{Breakfast intake at post-test}

Two significant interaction effects of study group by baseline value were found. In terms of vitamin C intake at breakfast on the day before questionnaire administration, we found a significant beneficial effect among students in the middle intake tertile at baseline. We found a significant beneficial intervention effect among students with the least desirable values at baseline for total saturated fat intake during the previous day.

Mixed regression analysis for breakfast behaviour did not show any school or class effects and no convincing differences in $B$-values were found compared to the fixed regression analysis.

\section{Discussion}

This study used a cluster-randomised design to investigate the effects on dietary behaviours of the Dutch healthful diet programme called Krachtvoer, intended for 12-14-year-old students of lower vocational schools. Fixed regression intention-to-treat analyses revealed beneficial effects on both outcome indicators related to fruit intake, and most behavioural indicators related to high-fat snack intake. With regard to breakfast habits, beneficial effects were only found for vitamin $\mathrm{C}$ and total saturated fat intake. Some positive behavioural effects occurred in the total target population, others mainly or only among students with the least desirable values at baseline. The mixed regression analysis found comparable $B$-values for the behavioural outcomes. However, the favourable effects on the two behavioural outcomes related to fruit intake were not significant in mixed regression analyses.

The behavioural effects regarding fruit are in line with the findings of previous research, which found programme effects of between 0.2 and 1 pieces of fruit ${ }^{28,29}$. No comparable effect studies on breakfast and snack consumption are available, since previous evidencebased programmes were mostly aimed at nutrients like total fat, energy and carbohydrates, rather than at specific breakfast or snacking behaviours. The fact that several programme effects were strongest or were only found among students with the least desirable values on dietary behaviour at baseline, can be considered to be additional favourable results, as they imply that it was especially the students who needed the programme the most who benefited the most from it.

Nevertheless, our findings are definitely not optimal. This might be due to intervention-related aspects as well as aspects of study methodology. We blame some implementation problems that were revealed by the process evaluation for the small or even the lack of beneficial effects on some outcome indicators ${ }^{30}$. The process evaluation indicated that the teachers implemented the programme largely according to plan, that the teachers appreciated most parts of the programme and that the students who were exposed to the programme perceived their nutritional lessons as significantly more pleasant, more interesting, easier and newer than students who followed the usual curriculum. However, especially the implementation of the last two lessons that were designed to translate positive behavioural intentions into actions was suboptimal. Degree of implementation was found to be influenced by the students' preferences. Some teachers did not implement the final lessons at all because they did not expect their students to appreciate the activities of those lessons. Developing alternatives for those activities that students do not appreciate can improve the programme's implementation. For some other programme components, it was concluded that a more intensive training programme for the teachers might result in greater intervention fidelity (degree to which a programme is implemented with its methods and strategies intact) ${ }^{19}$. 
We even found negative effects on the two behavioural measures related to fruit juice consumption in one subgroup. However, these might be due to the fact that students have difficulties distinguishing fruit juices from beverages that are not real fruit juices ${ }^{20}$. It is possible that the intervention made students better able to distinguish fruit juices from other beverages, as a result of which the reported fruit juice consumption at post-test was lower among those who reported initial high fruit juice consumption in the experimental group. Also a negative effect related to snack intake occurred among students with the most desirable values at baseline. The programme might have made these students aware of their relatively good eating habits and therefore the students might have allowed themselves to make some lesshealthful food choices. This negative effect was smaller than the positive effect for the students with the least desirable values at baseline. Nevertheless, the programme needs to be revised in order to prevent such effects among this subgroup of students.

The lack of effect on breakfast frequency may be related to the fact that $79 \%$ of the students already had breakfast on at least 5 days a week. Earlier studies on breakfast prevalence showed inconsistent results ${ }^{1,16,31}$, but in our study population, skipping breakfast was definitely not yet a major health behaviour problem. However, as eating breakfast has been found to decline rapidly during adolescence ${ }^{31}$, the Krachtvoer intervention might be effective in the longer run in that fewer students quit eating breakfast.

Important methodological considerations include our data analyses. At post-test, two control schools dropped out altogether and several students dropped out from the remaining 16 schools. We dealt with this problem by conducting intention-to-treat analyses as the primary analyses. We further took the clustering of students in classes and schools into account by checking all significant behavioural effects from the fixed regression analysis with the help of mixed regression analyses. Not all our positive findings were confirmed in these further analyses.

Another possible limitation is that all of the data were self-reported by students and may thus be subject to memory and recording errors. However, we included several self-reported measures, i.e. food frequency questions as well as recording of daily consumption, and results for these different self-reports were largely consistent. A final study limitation worth mentioning is that schools self-selected the classes that participated in the study. Schools might have chosen those classes in which they expected the programme implementation to be the easiest.

The potential effectiveness of the programme was supported by the results of secondary analyses that revealed beneficial effects on targeted behavioural determinants that were supposed to precede behavioural change, i.e. intention to change, attitudes, subjective norms, self-efficacy, awareness of risk behaviour, interest in the topics, perceived food rules and the availability and accessibility of food items at home. Similar to the behavioural effects, some of these favourable effects occurred in the entire target population, and others occurred mainly or only among those students who had the least desirable values at baseline ${ }^{32}$.

Although we did not find effects on all outcome indicators, the total pattern of results made us conclude that Krachtvoer had a certain surplus value over existing curricula. However, some parts of the programme need to be revised to improve its effectiveness and prevent negative effects among students with favourable intakes at baseline, and more information is needed about the long-term effects of the programme.

\section{Acknowledgements}

Sources of funding: This study was financially supported by the Netherlands Organisation for Health and Development (ZonMW) and the Netherlands Heart Foundation.

Conflict of interest declaration: None.

Authorship responsibilities: All the authors listed on this paper meet the criteria set down by the International Committee of Medical Journal Editors. No one who might consider that he or she has a right to be an author had been excluded.

\section{References}

1 Voedingscentrum. Zo eet Nederland, resultaten van de voedselconsumptiepeiling 1997-1998 [The Results of the Dutch National Food Consumption Survey 1997-1998]. Den Haag: Voedingscentrum, 1998.

2 Vereecken C, Ojala K, Delgrande Jordan M. Eating habits. In: Currie C, Roberts C, Morgan A, Smith R, Settertobulte W, Samdal O, et al., eds. Young People's Health in Context. Health Behaviour in School-aged Children (HBSC) Study: International Report from the 2001/2002 Survey. Copenhagen: World Health Organization Regional Office for Europe, 2004; 110-19.

3 World Health Organization (WHO). Diet, Nutrition and the Prevention of Chronic Diseases. Report of a Joint WHO/FAO Expert Consultation. WHO Technical Report Series, No. 916. Geneva: WHO, 2003. Available at http://whqlibdoc. who.int/trs/WHO_TRS_916.pdf. Accessed 10 February 2004.

4 Hirasing RA, Fredriks AM, Van Buren S, Verloove-Van Horick SP, Wit JM. Toegenomen prevalentie van overgewicht en obesitas bij Nederlandse kinderen en signalering daarvan aan de hand van internationale normen en nieuwe referentiediagrammen [Increased prevalence of overweight and obesity in Dutch children, and the detection of overweight and obesity using international criteria and new reference diagrams]. Nederlands Tijdschrift voor Geneeskunde 2001; 145: 1303-8.

5 World Health Organization (WHO). Life in the 21st Century - A Vision for All. The World Health Report. Geneva: WHO, 1998. 
6 Kelder SH, Perry CL, Klepp KI, Lytle LL. Longitudinal tracking of adolescent smoking, physical activity, and food choice behaviors. American Journal of Public Health 1994; 84: 1121-6.

7 Lytle LA, Seifert S, Greenstein J, McGovern P. How do children's eating patterns and food choices change over time? Results from a cohort study. American Journal of Health Promotion 2000; 14: 222-8.

8 Contento IR, Randell JS, Basch CE. Review and analysis of evaluation measures used in nutrition education intervention research. Journal of Nutrition Education and Behavior 2002; 34: 2-5.

9 Hoelscher DM, Evans A, Parcel GS, Kelder SH. Designing effective nutrition interventions for adolescents. Journal of the American Dietetic Association 2002; 102: S52-63.

10 Contento IR, Michela JL. Nutrition and food choice behavior among children and adolescent. In: Goreczny AJ, Hersen M, eds. Handbook of Pediatric and Adolescent Health Psychology. Boston, MA: Allyn \& Bacon, 1999; 1-38.

11 Perez-Rodrigo C, Aranceta J. Nutrition education in schools: experiences and challenges. European Journal of Clinical Nutrition 2003; 57: S82-5.

12 Contento IR, Balch GI, Bronner YL, Lytle LA, Maloney SK, Olson CM, et al. The effectiveness of nutrition education and implications for nutrition education policy, programs and research: a review of research. Journal of Nutrition Education 1995; 27(special issue).

13 Blanchette L, Brug J. Determinants of fruit and vegetable consumption among six to twelve-year-old children and effective interventions to increase consumption. Journal of Human Nutrition and Dietetics 2005; 18: 431-43.

14 Bere E, Veierod MB, Bjelland M, Klepp KI. Outcome and process evaluation of a Norwegian school-randomized fruit and vegetable intervention: fruits and vegetables make the marks (FVMM). Health Education Research 2006; 21: 258-67.

15 Klepp KI, Perez Rodrigo C, De Bourdeaudhuij I, Due P, Elmadfa I, Haraldsdottir J, et al. Promoting fruit and vegetable consumption among European schoolchildren: rationale, conceptualization and design of the Pro Children Project. Annals of Nutrition \& Metabolism 2005; 49: 212-20.

16 De Vries M, Da Costa Senior R. Scholieren en tussendoortjes: onderzoek naar eet -en drinkgewoonten tijdens schooltijd van leerlingen in het basis en voortgezet onderwijs in Midden-Holland [Research into Eating and Drinking Habits During School Ours Among Students of Secondary Schools and High Schools]. Gouda: GGD Midden Holland, 1992.

17 Koivisto Hursti UK. Factors influencing children's food choice. Annals of Medicine 1999; 31: 26-32.

18 Roos E, Lahelma E, Virtanen M, Prattala R, Pietinen P. Gender, socioeconomic status and family status as determinants of food behaviour. Social Science \& Medicine 1998; 46: 1519-29.
19 Bartholomew LK, Parcel GS, Kok G, Gottlieb N. Intervention Mapping: Designing Theory and Evidence-based Health Promotion Programs. California: Mayfield Publishing Company, 2001.

20 Martens M, Wind M, Van Assema P, Brug J. De (on) mogelijkheden van voedingsvoorlichting aan twaalf- tot veertienjarige jongeren [Opportunities and pitfalls of nutrition education for adolescents aged 12-14]. Nederlands Tijdschrift voor Diëtisten 2002; 57: 71-7.

21 Martens M, Brug J. Why do adolescents eat what they eat? Personal and social environmental predictors of fruit, snack and breakfast consumption among 12-14-year-old Dutch students. Public Health Nutrition 2005; 8: 1258-65.

22 Van Assema P, Brug J, Ronda G, Steenhuis I, Oenema A. A short Dutch questionnaire to measure fruit and vegetable intake: relative validity among adults and adolescents. Nutrition and Health 2002; 16: 85-106.

23 Van Assema P, Brug J, Ronda G, Steenhuis I. The relative validity of a short Dutch questionnaire as a means to categorize adults and adolescents to total and saturated fat intake. Journal of Human Nutrition and Dietetics 2001; 14: 377-90.

24 Donders-Engelen M, Van der Heijden L, Hulshof K. Maten gewichten en codenummers. Wageningen: Afdeling Humane Voeding Wageningen, 2003.

25 Snijders TAB, Bosker RJ. Multilevel Analysis. An Introduction to Basic and Advanced Multilevel Modelling. London: Sage, 1999.

26 Rasbash J, Browne W, Goldstein H, Yang M, Plewis I, Draper D, et al. A User's Guide to MlWin. London: Institute of Education, 1999.

27 Verbeke G, Molenberghs G. Linear Mixed Models for Longitudinal Data. New York: Springer, 2000.

28 Contento I, Balch GI, Bronner YL, Lytle LA, Maloney SK, White SL, et al. The effectiveness of nutrition education and implications for nutrition education policy, programs and research: nutrition education for school-aged children. Journal of Nutrition Education 1995; 27: 298-311.

29 Ammerman AS, Lindquist $\mathrm{CH}$, Lohr KN, Hersey J. The efficacy of behavioral interventions to modify dietary fat and fruit and vegetable intake: a review of the evidence. Preventive Medicine 2002; 35: 25-41.

30 Martens M, vanAssema P, Paulussen GW, Schaalma H, Brug J. Krachtvoer: process evaluation of a Dutch programme for lower vocational schools to promote healthful diet. Health Education Research 2006; 21: 695-704.

31 Currie C, Roberts C, Morgan A, Smith R, Settertobulte W, Samdal O, et al. Young People's Health in Context. Health Behavior in School-aged Children (HBSC) Study: International Report from the 2001/2002 Survey. Copenhagen: World Health Organization Regional office for Europe, 2004.

32 Martens MK. Krachtvoer: The Development, Implementation, and Evaluation of an Educational Programme for 12-14-year-old Students to Promote Healthy Eating. Maastricht: Maastricht University, 2005. 